\title{
The implementation of the Fulbright English teaching assistant program in Malaysia: An evaluation on students' language proficiency
}

\author{
Mazura Mastura Muhammad ${ }^{1, *}$, Chan Siang Jack ${ }^{1}$, Sahandri Gani Hamzah ${ }^{2}$ \\ ${ }_{1}^{1}$ Faculty of Languages and Communication, Sultan Idris Education University, Perak, Malaysia \\ ${ }^{2}$ Faculty of Education and Human Development, Sultan Idris Education University, Perak, Malaysia
}

\section{A R T I C L E I N F O}

\section{Article history:}

Received 17 February 2017

Received in revised form

15 April 2017

Accepted 16 April 2017

\section{Keywords:}

English teaching assistant program

Co-teach

Non-co-teach

MBMMBI Policy

English language proficiency

\begin{abstract}
A B S T R A C T
Few research has been conducted to investigate the effectiveness of the ETA Program in enhancing the students' English Language (EL) proficiency since its implementation in 2012. This study aims to evaluate the ETA Program implemented in Malaysian secondary schools. This study employed both qualitative (interviews) and quantitative methods (written and oral tests) in data collection involving a total of nine (9) rural secondary schools in seven (7) states. Additionally, a total of 59 EL teachers and 399 students, were selected for the study. Written and oral tests results showed significant differences between the performances of students who were guided by the ETA (co-teach classes) and students who were not guided by the ETA (nonco-teach classes). However, the written and oral test scores of students from co-teach classes were not significantly better than students from non-coteach classes. The mean scores for both written and oral tests of students in co-teach classes were low and not at satisfactory level. Although the interviews with the EL teachers revealed that the ETA Program helps in enhancing the students' motivation and interest in using EL, it does not boost the students' academic performances. In conclusion, the ETA Program has a positive impact on the students' confidence level and interest in using English language, this impact however, is still low and does not have a profound effect on the students' overall EL proficiency.
\end{abstract}

(C) 2017 The Authors. Published by IASE. This is an open access article under the CC BY-NC-ND license (http://creativecommons.org/licenses/by-nc-nd/4.0/).

\section{Introduction}

'Memartabatkan Bahasa Malaysia Memperkukuh Bahasa Inggeris' (MBMMBI) or Upholding Bahasa Malaysia and Strengthening English Language (Circulation 2/2010) is a new government policy initiated to replace the Pengajaran dan Pembelajaran Sains dan Matematik dalam Bahasa Inggeris (PPSMI) or in English, the Teaching of Science and Mathematics in English language, which was found ineffective in its implementation. The chief aims of the MBMMBI Policy are first, to uphold the Malay language in line with the Education Act 1996 which emphasizes Malay language as the medium of instruction in all primary and secondary schools. Second, the policy also aspires to strengthen the English language mastery among Malaysian students, enabling them to explore knowledge which is more accessible in this international language.

\footnotetext{
* Corresponding Author.

Email Address: mazura@fbk.upsi.edu.my (M. M. Muhammad) https://doi.org/10.21833/ijaas.2017.06.017

2313-626X/C 2017 The Authors. Published by IASE.

This is an open access article under the CC BY-NC-ND license

(http://creativecommons.org/licenses/by-nc-nd/4.0/)
}

To materialize the MBMMBI policy, the Ministry of Education (MOE) has laid out eight strategies in support of the policy. One of the strategies is the Fulbright English Teaching Assistant Program (ETA Program). The ETA Program is a collaboration between the Malaysian and the American governments and it is jointly supervised by the MOE and the Malaysian-American Commission on Educational Exchange (MACEE). The ETA Program commenced in the year 2012 and schools with low performance in English from Band 5 or 6 are selected for the program. It endeavors to; first, increase the students' interest towards English and thus, improve their communicative skills; second, enhance students' ability and confidence in using English; third, encourage students to actively participate in curricular and co-curricular activities; and finally, engage students in cultural exchange activities.

On the 27th April 2014, during a meeting held between the Malaysian government with the United States of America, the Prime Minister of Malaysia and the President of the United States of America came to an agreement that the ETA Program which then had been implemented for two years, will be 
further extended for another 3 years (2015 - 2017). In addition, a total amount of RM18 million will be invested for the ETA Program through the MBMMBI policy for those 3 years' time, where 100 ETAs will be placed in the chosen schools in Malaysia each year.

Since its inception in 2012, the ETA Program has yet to be subjected under rigorous research. There is little research conducted to ascertain the program's effectiveness, especially on the students' EL proficiency. For a large-scale international education program, an evaluation on the program is crucial to ascertain the efficiency and efficacy of its implementation. Such evaluation will provide invaluable insights on the detailed implementation of the program highlighting its strengths and weaknesses. Hence, the current study aims to determine the students' spoken and written level of proficiency in the implementation of the Fulbright English Teaching Assistant Program in Malaysia. This helps to ascertain the effectiveness of the ETA Program.

\section{Problem statement}

In the year 2003, the MOE implemented the PPSMI policy in Malaysian schools under the resolution of the Malaysian Cabinet on the 19th of July 2002. The policy stresses on the use of English language as the medium of instruction in the teaching of Mathematics and Science, for the purpose of improving students' command of English in Malaysian schools.

However, it was found that the PPSMI policy had failed to achieve its objectives and more importantly the students' achievement in the Science and Mathematics subjects had dwindled (Gonzales et al., 2007). This, consequently, widened the gap between the students in rural and urban schools in terms of achievement of these subjects (Gonzales et al., 2007). The PPSMI was, thus, abolished in 2009 and in its place; the MBMMBI Policy was introduced in 2010.

The MBMMBI Policy strives to enhance students' mastery in Bahasa Malaysia and reinforce their proficiency in English language. English language is reinforced through several strategies and one of the most notable strategies is the implementation of Fulbright English Teaching Assistant (ETA) Program. Since its implementation, studies have yet to be conducted to ascertain the effectiveness of the program in Malaysia. The current study primarily concentrated on the implementation of MBMMBI Policy. This study, however, will focus on the evaluation of the ETA Program in Malaysian secondary schools. Hence, this research was carried out to:

- gauge the oral and written proficiency of students in classes guided by ETAs; and

- compare the oral and written proficiency of students guided by ETAs with students who were not guided the ETAs
In addition, this research aims to answer the following research questions:

- What is the oral and written proficiency of students guided by ETAs?

- Are there any discrepancies in the language proficiency of the students guided by ETAs and students who were not guided by the ETAs?

\section{Methodology}

The current study the typical procedure in the first phase involves collecting quantitative data by conducting written and oral test scores. These tests were then scored by highly trained language instructors. Subsequently, the qualitative data was collected via interviews with the purpose of explaining the quantitative data. The combination of both quantitative and qualitative methods provides a better understanding on the actual implementation of the ETA Program in Malaysian secondary schools. Cohen et al. (2013) purported that the use of both quantitative and qualitative methods for data collection is significantly better, as it allows a more critical evaluation on the data, in this case the evaluation of the ETA Program.

\subsection{Phase 1}

Phase 1 of research implementation procedure involves the use of a set of writing and oral tests. The researcher conducted written and oral tests on students of both classes to observe the English language proficiency of two classes - first, a class where co-teach sessions were implemented and second, a class where co-teach sessions were not implemented. In other words, the tests were conducted on classes that were guided by ETAs and classes which were not guided by the ETAs.

Using Statistical Package for Social Science (SPSS) software, students' written test and oral test scores were analyzed using T-Test procedure to compare the discrepancy of students' test scores between coteach classes and non-co-teach classes. In addition, ttest is also able to provide the mean scores that would enable the researcher to compare the mean scores for both written and oral test between students from co-teach classes and students from non-co-teach classes. Crosstabs was also conducted to properly summarize and arrange the data between co-teach classes and non-co-teach classes with the test scores that the students obtained in both classes. In addition, a bivariate Pearson's correlation was conducted between written test scores and oral test scores to determine the empirical relationship between them.

\subsection{Phase 2}

Phase 2 of the Qualitative Data Collection Procedure involved interview sessions with head of EL Panel and EL teachers. All heads of English 
language panel and EL teachers were interviewed in this study.

Pseudo names are used to conceal the identities of the respondents, at such that they identities will not be revealed as a part of research ethics. Table 1 below shows the pseudo names used to indicate schools, teachers, and ETAs involved in this study.

Table 1: Pseudo names used in indicating schools, teachers, and ETA

\begin{tabular}{ccc}
\hline Schools & Teachers & ETA \\
\hline S1 & T1 & TA1 \\
S2 & T2 & TA2 \\
S3 & T3 & TA3 \\
S4 & T4 & TA4 \\
S5 & T5 & TA5 \\
$\ldots$ & $\ldots$ & $\ldots$ \\
\hline
\end{tabular}

\subsection{Research sampling}

As aforementioned, research samples were selected using the stratified random sample selection method. Krejcie and Morgan (1970) explain that researchers often face difficulty of getting access to a large sampling population, as it can be too expensive and time-consuming. Hence, they resort to a population based on a representative sample allowing them to make generalization from the selected samples.

The stratified random sampling method refers to the division of sample population according to strata or subsets, and stratification variables that can be considered include age group, job status, gender and other variables. In the current study, the stratification variable chosen is the location of the schools divided based on the zones - northern, central, southern, eastern and SQL zones (Sabah, Sarawak and Labuan).

The stratified random sampling method is considered practical as the sampling method generally provides increased accuracy in sample estimates without resulting in a substantial increase in cost and time. In addition, it enables the researcher to gain more precise information of the entire population (Teddlie and $\mathrm{Yu}, 2007$ ).

In 2016, the ETA Program is implemented in 100 schools involving 100 ETAs. Due to cost and time constraints, a total of nine (9) schools were selected for the current study. This selection covers the four zones in Malaysia. For each zone, two schools were selected. Table 2 summarizes the samples of the current research.

Table 2: Number of schools and samples according to zones

\begin{tabular}{ccccccc}
\hline \multirow{2}{*}{ Zones } & \multirow{2}{*}{ States } & \multicolumn{5}{c}{ Research Sample } \\
\cline { 3 - 7 } & Kedah & Number of Schools & Head of English language Panel & English language teachers & ETA & Students \\
\hline \multirow{2}{*}{ North } & Perlis & 1 & 1 & 6 & 1 & 43 \\
Middle/Centre & Perak & 2 & 1 & 6 & 1 & 32 \\
East & Kelantan & 1 & 1 & 12 & 2 & 78 \\
& Terengganu & 1 & 1 & 6 & 1 & 50 \\
SQL & Sabah & 1 & 1 & 5 & 1 & 30 \\
TOTAL & Sarawak & 2 & 1 & 6 & 1 & 40 \\
& 7 & 9 & 9 & 59 & 1 & 126 \\
\hline
\end{tabular}

As mentioned above, two schools in each zone were selected for the research except for the SQL zone, in which three schools were chosen. The states in the north that were involved in the study were Kedah and Perlis with two schools. Meanwhile, in the central zone two schools in the Perak state were chosen to participate in the study. East zone involved the states of Kelantan and Terengganu, where one school was chosen for each state, respectively. Last but not least, the SQL zone covered the states Sabah and Sarawak, where one school in Sabah and two schools from Sarawak were selected to participate in this study.

A total of nine heads of EL Panel, 59 EL teachers and 399 secondary students were involved in this study. Out of 399 students, 165 students were Form 2 students, while Form 4 students encompassed 234 students. Among the 165 Form 2 students, 82 of them are from co-teaching classes and 83 students are from non-co-teach classes. For Form 4 students, 130 students are from co-teaching classes, while the remaining 104 students are from non-co-teach classes. Forms 2 and 4 students were chosen as the research samples since ETAs were only assigned to conduct co-teach with EL teachers in nonexamination classes. The implementation of ETA
Program does not involve examination classes to avoid disruption of the syllabus allowing the students to concentrate for the incoming examinations.

\subsection{The oral and written test}

Since it is difficult to properly measure level of 'confidence' or 'interest' of students in using EL, the current study aims to gauge the productive skills of the students via the written and oral tests. Students who have confidence and interest in EL would result in more successful language mastery. Students' confidence and interest in the English Language facilitates language learning; which in turn increases the students' communicative skills (McCroskey, 1970). Hence, in the current study the writing and oral tests were used as a platform to measure the students' confidence and interest.

The written and oral tests were divided into 2 sub-categories namely Category 1 , which is for students of lower form (Form 2), while Category 2 involves students of upper form (Form 4). The reason of dividing the test into two different groups is due to the availability of the sample students in each school when the survey was conducted. 
The writing and oral tests were conducted in both classes; co-teach and non-co-teach classes. The rationale was to make a comparison of oral proficiency between students who are involved in the co-teaching sessions with the students who were not involved in the co-teaching sessions.

Written tests were conducted to determine the EL proficiency of the students. Students from both Categories 1 and 2 were given a series of pictures entitled "Reduce, Reuse, and Recycle". Students from Category 1 (Form 2) were required to write a simple essay consisted of a minimum of one paragraph. As for students from Category 2 (Form 4), they were required to write an essay of at least three paragraphs. These requirements are in line with requirements of major exams in Malaysia (i.e. PT3 and SPM). Additionally, the topic "Reduce, Reuse, Recycle" was chosen because first, the theme "Environment" is included in the Curriculum Specifications of Forms 2 and 4; and second, the topic "Reduce, Reuse, Recycle" is part of the topics in Forms 2 and 4 textbooks.

The oral tests consisted of different black and white comic strips by LAT. LAT's cartoons heighten the spirit of nationalism and nation-building (Rahman, 2012) and these cartoons exhibit things, events and actions that are common in the daily lives of all Malaysians (Bahfen et al., 2014). Thus, the students were given these comic strips as they were able to relate to them and they depict today's images of cultural practices, norms and activities. Before the oral tests were conducted, the cartoons were shown to the students and they were then given 1 minute to prepare their presentation based on these cartoons. The students were given approximately two minutes to describe the cartoons. This procedure was employed to both Category 1 and Category 2 students.

The marking schemes for both oral and written tests are different for Category 1 and Category 2 . The written and oral tests for Category 2 students (Form 4) were assessed based on Sijil Pelajaran Malaysia
(SPM) or Malaysian Certificate of Education which is currently used to assess the writing ability of secondary school students. As for the students of Category 1 (Form 2), the marking rubric used is taken from the PT3 writing and oral marking guidelines.

Using SPSS software, students' written test and oral test scores were analyzed using T-Test procedure to compare the discrepancy of students' test scores between co-teach classes and non-coteach classes. In addition, t-test is also able to provide the mean scores that would enable the researcher to compare the mean scores for both written and oral test between students from coteach classes and students from non-co-teach classes. Crosstabs was also conducted to properly summarize and arrange the data between co-teach classes and non-co-teach classes with the test scores that the students obtained in both classes. In addition, a bivariate Pearson's correlation was conducted between written test scores and oral test scores to determine the empirical relationship between them.

\section{Results}

This section aims to gauge the language proficiency of the students who were under the guidance of ETAs. It also targets to determine the discrepancies in language proficiency between students who were guided by the ETAs and students who were not. The ETA Program aims to improve the students' communicative skills and ability in using English. Hence, it is imperative to measure the students' language proficiency to determine the progress of the students under the guidance of ETAs.

The findings presented in this section are divided into two sections - Form 2 and Form 4. Table 3 shows the comparison of Pearson Correlation values between the students' written and oral test scores.

Table 3: Pearson correlation between the oral and written test scores

\begin{tabular}{ccccc}
\hline \multirow{2}{*}{ Variables } & \multicolumn{2}{c}{ Form 2} & \multicolumn{2}{c}{ Form 4 } \\
\cline { 2 - 5 } & Pearson (r) & Significant & Pearson (r) & Significant \\
\hline Written $\leftarrow \rightarrow$ Oral & 0.359 & 0.000 & 0.394 & 0.000 \\
\hline \multicolumn{4}{c}{ Significant $=<0.01$}
\end{tabular}

Table 3 shows the comparison of Pearson Correlation values and two-tailed probability between the students' written and oral test scores. The analysis shows that the correlation between written and oral test scores is significant (Form 2: $\mathrm{r}=$ 0.359; Form 4: $r=0.394$ ). In short, the results conclude that the students' written and oral test scores are related and dependent on each other. In other words, the students' oral capabilities affected their written capabilities and vice versa. The results of the study seem to echo August and Shanahan (2006) assertion on the relationship between oral language proficiency and English reading comprehension and writing skills.

\subsection{Students' English language proficiency}

\subsubsection{English language proficiency of form 2 students}

Table 4 below shows the written test scores for Form 2 students between co-teach and non-co-teach classes. Overall, the current study involved 165 Form 2 students and out of these, 82 students were in coteach classes and 83 were from non-co-teach classes (Section 3.3). The number of students from both classes was almost balanced.

The findings show that out of 82 students from the co-teach classes, the scores of $53.7 \%$ (44 students) fell under the Very Weak level; while 
$32.9 \%$ (27) of the students were categorized under the Weak level. Furthermore, only $9.8 \%$ (8 students) obtained satisfactory scores and scores from $3.7 \%(3$ students) were classified as Good. In other words, more that $40 \%$ of the students from the co-teaching classes were weak in their writing ability.

Table 4: Form 2 students' written test scores between coteach and non-co-teach classes

\begin{tabular}{ccc}
\hline \multirow{3}{*}{ teach and non-co-teach classes } \\
\cline { 2 - 3 } Students' Written test scores level & \multicolumn{2}{c}{ Classes } \\
\cline { 2 - 3 } & Co-teach & Non-co-teach \\
\hline Very Weak $(0-2)$ & $44(53.7 \%)$ & $68(81.9 \%)$ \\
Weak $(3-4)$ & $27(32.9 \%)$ & $11(13.3 \%)$ \\
Satisfactory $(5-6)$ & $8(9.8 \%)$ & $3(3.6 \%)$ \\
Good $(7-8)$ & $3(3.7 \%)$ & $1(1.2 \%)$ \\
Excellent $(9-10)$ & - & - \\
Total & $100 \%(82)$ & $100 \%(83)$ \\
\hline
\end{tabular}

Students from the non-co-teach classes, however, seemed to fair worse than students from co-teaching classes. The scores from majority of the students $(81.9 \%)$ were at the Very Weak level; while $13.3 \%$ (11 students) were categorized as Weak. There were only 3.6\% (3 students) with satisfactory scores; and unfortunately, only one student $(1.2 \%)$ who scored Good.

The comparison shows that there were no significant differences between the writing test scores of students from the co-teaching and non-coteaching classes. In other words, the performance of the students from both classes was alike. With the presence and guidance of the ETAs, students who were privileged to be under the tutelage of the ETAs should be faring better than those who were not. The findings from the current study seem to suggest otherwise. Table 5 presents the T-Test analysis on Form 2 students' writing test scores between coteach and non-co-teach classes.

Table 5: T-test analysis on form 2 students' written test scores between co-teach and non-co-teach classes

\begin{tabular}{ccccccc}
\hline Class & $\mathrm{N}$ & Mean (Test scores) & Standard deviation (SD) & df & T-value & Sig \\
\hline Co-teach & 82 & 2.463 & 1.861 & 163 & -3.581 & 0.000 \\
Non-co-teach & 83 & 1.542 & 1.417 & & & \\
\hline
\end{tabular}

The T-Test analysis shows that there are significant differences between the written test scores for students in co-teach classes where (mean $=2.463, \mathrm{SD}=1.861$ ) and non-co-teach classes (mean $=1.542, \mathrm{SD}=1.417$ ), with conditions; $\mathrm{t}=-3.581, \mathrm{p}=$ 0.000 . Despite the differences between the students' written test scores for both students in co-teach and non-co-teach classes, the writing test scores for both classes were very low, with the mean score of 2.4 out of 10 marks for co-teach classes, while the mean score for non-co-teach class is 1.5 out of 10 . The means of writing scores for both the co-teaching and non-co-teaching classes are very low. Some students from co-teaching classes struggled to string proper sentences in their writing tests and some did not attempt to complete the writing tasks at all. The findings show that the assistance and guide from ETAs had little effect on the students' writing ability.

The comparison of the oral performance between Form 2 students who received assistance from the ETAs and those who did not will be dealt next. Table 6 shows the oral test scores for Form 2 students in both co-teach and non-co-teach classes.

Table 6: Form 2 students' oral test scores between coteach and non-co-teach classes

\begin{tabular}{ccc}
\hline \multirow{2}{*}{ Students' Oral test scores level } & \multicolumn{2}{c}{ Classes } \\
\cline { 2 - 3 } & Co-teach & Non-co-teach \\
\hline Very Weak & $26(31.7 \%)$ & $41(49.4 \%)$ \\
Weak & $48(58.5 \%)$ & $39(47.0 \%)$ \\
Average & $5(6.1 \%)$ & $3(3.6 \%)$ \\
Good & $2(2.4 \%)$ & - \\
Excellent & $1(1.2 \%)$ & - \\
Total & $100 \%(82)$ & $100 \%(83)$ \\
\hline
\end{tabular}

The findings show that the oral test scores of 26 students $(31.7 \%)$ in the co-teach classes were categorized under Very Weak level; while majority of the students (48 students or 58.5\%) fell under the Weak level. Five (6.1\%) students' oral scores were under the Average level, two students (2.4\%) under the Good level and only one (1.2\%) student's scores is classified under Excellent level. Unlike the students from the co-teach class, majority of the students' (41 students or 47\%) oral test scores from non-co-teach classes fell under the Very Weak level. None of the students in the non-co-teach classes scored above average in their oral test. As expected, none of the students' oral performance from the nonco-teach classes can be categorized under the Good and Excellent levels. In other words, the students from the co-teach classes seem to fare better than the students from non-co-teach classes. The results also seem to be pointing out that despite the assistance from ETAs, majority of the students could not score above average and only three students from the total 82 students obtained scores above average. Table 7 shows the T-Test comparison of Form 2 students' oral test scores between co-teach and non-co-teach classes.

The results presented above indicate that there are significant differences between the Form 2 students' oral test scores from co-teach classes and non-co-teach classes $(\mathrm{t}=-3.105 . \mathrm{p}=0.000)$. This was due to the differences of the average test scores mean between students in the co-teach classes (mean $=4.4756, \mathrm{SD}=2.069)$ and the students in non-co-teach classes (mean $=3.5904, \mathrm{SD}=1.562$ ). Despite the significant differences in the students' oral test scores between co-teach and non-co-teach classes, the test scores for both classes were still considered low. With the guidance from ETAs, students from the co-teach classes should significantly score better and higher than students from non-co-teach classes.

Overall, the findings show that students' proficiency in oral and written English from co-teach classes is still very low. It is understandable that students who did not receive the assistance from ETAs did not fare well in both oral and writing tests, 
but the students who received the guidance from ETAs seemed to perform only slightly better than these students. Each school chosen in this study had received the assistance from ETAs for a minimal of two years.

Table 7: T-test analysis on form 2 students' oral test scores between co-teach and non-co-teach classes

\begin{tabular}{ccccccc}
\hline Class & $\mathrm{N}$ & Mean (Test scores) & Standard deviation (SD) & $\mathrm{df}$ & $\mathrm{T}$-value & Sig \\
\hline Co-teach & 82 & 4.4756 & 2.069 & 163 & -3.105 & 0.000 \\
Non-co-teach & 83 & 3.5904 & & & & \\
\hline
\end{tabular}

Since the arrival of ETAs in the schools, EL activities such as co-teaching in selected classes with EL teachers, Speaking Workshops and Click Camps had been planned and conducted to increase students' ability in English. In other words, despite the efforts taken by the parties involved in ETA program to increase the students' English language proficiency, the findings of the study reveal that the intervention did not significantly impact the students' English language speaking and writing skills.

\subsubsection{English language proficiency of form 4 students}

Table 8 shows the writing test scores of Form 4 students in both co-teach and non-co-teach classes. The Form 4 students who were involved in the current study encompassed 234 students. Out of the total number of students, 130 students were from co-teaching classes, while 104 were from non-coteach classes.

Table 8: Form 4 students' written test scores between co-teach and non-co-teach classes

\begin{tabular}{cccc}
\hline \multirow{2}{*}{ Achievement Level } & \multirow{2}{*}{ Students' Written test scores level } & \multicolumn{2}{c}{ Classes } \\
\cline { 3 - 4 } & & Co-teach & Non-co-teach \\
\hline & $\mathrm{U}(\mathrm{iii})$ & $3(2.3 \%)$ & $64(61.5 \%)$ \\
Poor & $\mathrm{U}(\mathrm{ii})$ & $57(43.8 \%)$ & $22(21.2 \%)$ \\
& $\mathrm{U}(\mathrm{i})$ & $66(50.8 \%)$ & $15(14.4 \%)$ \\
Unsatisfactory & $\mathrm{E}$ & $4(3.1 \%)$ & $3(2.9 \%)$ \\
Passable & $\mathrm{D}$ & - & - \\
Satisfactory & $\mathrm{C}$ & - & - \\
Good & $\mathrm{B}$ & - & - \\
Excellent & $\mathrm{A}$ & $100 \%(130)$ & $100 \%(104)$ \\
\hline
\end{tabular}

The findings show that out of the 130 Form 4 students from co-teach classes, $2.3 \%$ (3 students) of the students' writing test scores fell under U(iii) Level (Poor); while an astonishing 43.8\% (57 students) of them scored U(ii) Level (Poor). Majority of the students in the co-teach classes (66 students; $50.8 \%$ ) scored U(i) Level (Poor). 3.1\% of the students (4 students) scored E or Unsatisfactory level in their writing tests.

For students from non-co-teaching classes, the findings show that majority of the students (64 students; 61.5\%) scored U(iii) Level (Poor), while $21.2 \%$ (22 students) of them scored U(ii) Level (Poor) in their writing tests. Also, only 15 students
(14.4\%) obtained U(i) Level (Poor) and three (2.9\%) students of the total 104 students scored E Level (Unsatisfactory) in the writing tests.

Comparing both classes, the results of the students writing test scores exhibit minute differences. The test scores of students from both classes fall under the Poor Level. The students from the co-teach classes should perform better and obtain higher scores compared to the students from non-co-teach classes. However, the results from this study do not support this notion. Table 9 presents the T-Test analysis on Form 4 students' writing test scores between co-teach and non-co-teach classes.

Table 9: T-test analysis on form 4 students' written test scores between co-teach and non-co-teach classes

\begin{tabular}{ccccccc}
\hline Class & $\mathrm{N}$ & Mean (Test scores) & Standard deviation (SD) & $\mathrm{df}$ & $\mathrm{T}$-value & Sig \\
\hline Co-teach & 130 & 3.746 & 1.470 & 232 & -9.571 & 0.000 \\
Non-co-teach & 104 & 1.644 & 1.890 & & & \\
\hline
\end{tabular}

The results indicate that there are significant differences in the Form 4 students' writing test scores between co-teach and non-co-teach classes $(t=-9.571$. $p=0.000)$. This was due to the differences in the average means of test scores between co-teach classes (mean $=3.7462, \mathrm{SD}=1.470)$ and non-coteach classes (mean $=1.6442, \mathrm{SD}=1.890$ ). Nonetheless, the average mean of test scores for coteach classes was low; with the score of 3.7 out of 10 marks, while the average test scores for non-coteach classes was 1.6. Despite the significant differences, it is worth noted that the scores for both classes were under the Poor level, including the students in co-teach classes, who were guided by the ETAs for a minimum of two years.

Subsequently, Table 10 shows the oral test scores for Form 4 students in both co-teach and non-coteach classes. Similar to the oral tests for the Form 2 students, the marking rubric was taken from the PT3.

The findings show that $95.2 \%$ of the students from non-co-teach classes were categorized under Weak and Satisfactory levels. For the co-teach classes, $80.9 \%$ of the students fell under the Weak 
and Satisfactory levels. In other words, majority of the students from both co-teach and non-co-teach scored Satisfactory level and below and only $4.8 \%$ (non-co-teach) and 19.1\% (co-teach) of the students scored Good level and above.

Table 10: Form 4 students' oral test scores between coteach and non-co-teach classes

\begin{tabular}{ccc}
\hline Students' Oral test & \multicolumn{2}{c}{ Classes } \\
\cline { 2 - 3 } scores level & Co-teach & Non-co-teach \\
\hline Weak & $24(18.5 \%)$ & $57(54.8 \%)$ \\
Satisfactory & $85(65.4 \%)$ & $42(40.4 \%)$ \\
Good & $19(14.6 \%)$ & $4(3.8 \%)$ \\
Excellent & $2(1.5 \%)$ & $1(1.0 \%)$ \\
Total & $100 \%(130)$ & $100 \%(104)$ \\
\hline
\end{tabular}

The findings disclose that there was a discrepancy between the oral performance of the students from the co-teaching and non-co-teaching classes (95.2\% and 80.9\%), the discrepancy, however, was marginal (14.3\%). Next, the analysis of T-Test on Form 4 students' oral test scores between co-teaches and non-co-teach classes are presented in the Table 11.

The results presented in Table 9 show that there are significant differences in students' oral test scores between co-teach classes and non-co-teach classes $(t=-4.940 . p=0.000)$. The differences are due to the average mean of test scores between students in co-teach classes $($ mean $=5.2538, \mathrm{SD}=2.347)$ and the students in non-co-teach classes (mean $=3.8077$, $\mathrm{SD}=2.063$ ). However, the average mean scores for students' oral test was less than half of the total oral scores. The average mean score for students in coteach class was only 5.2 while the average score for students in the non-co-teach class was only 3.8 out of 15 marks. It is worth noted that some of the students in co-teach classes especially, could not perform well and were having difficulties in constructing sentences. Some of the students also claimed that they could not speak English and most of them struggled to construct a story based on the stimulus given in the oral tests.

Table 11: T-test analysis on form 4 students' written test scores between co-teach and non-co-teach classes

\begin{tabular}{ccccccc}
\hline Class & $\mathrm{N}$ & Mean (Test scores) & Standard deviation (SD) & $\mathrm{df}$ & $\mathrm{T}$-value & Sig \\
\hline Co-teach & 130 & 5.2538 & 2.347 & 232 & -4.940 & 0.000 \\
Non-co-teach & 104 & 3.8077 & 2.063 & & & \\
\hline
\end{tabular}

Based on the overall findings presented above, it clearly shows that the ETA Program had a minimal impact on the students' written and oral proficiency. Despite the differences and significance in both oral and written test scores between students in co-teach and non-co-teach classes, the average scores for both written and oral tests were low.

\subsection{Interview with the head of English language panel and English language teachers}

This subsection presents the qualitative findings gathered from the interview sessions with the heads of EL panel and EL teachers regarding their perspective towards the ETA Program on students' overall proficiency level.

The findings reveal that the implementation of the ETA Program helped to increase the students' confidence is using the language, particularly their speaking ability. ETA helped to boost the students' confidence to use English by creating more opportunities for them to communicate with their classmates and friends. Thus, this affected their EL oral proficiency. The presence of ETAs in the classrooms motivated the students to learn and the variety of teaching approaches used during coteaching sessions had propelled the students' participation during EL lessons. The students felt that the activities conducted by the ETAs were entertaining and made them feel enthusiastic whenever the ETAs entered the class. Among the EL teachers' responses:

S4T3: ETA helps the students in motivating them. The students are more enthusiastic in learning. They will see me as the serious ones and the other one is something fun and enjoyable", "for the lower form, the students really eager to learn and speak English when she (ETA) is around.

S5T1: They are very enthusiastic and it somehow affected their EL proficiency. Like they like to speak, try to get the message across, try to ask their friends on how to say certain things in English.

S7T1: I can see that students are more interested in using English with their peers and they like to talk to the ETA - (Interview transcription with S4T3, S5T1, S7T1)

This finding is consistent with the findings in Section 4.1. Despite increasing the students' level of confidence in using the language and improving the students' oral proficiency, the heads of EL panel and EL teachers felt that the ETA Program did not have significant impact on the overall EL proficiency of the students. In fact, these improvements could not be seen in the students' examination results. In addition, some EL teachers reported that the ETAs did not focus on the teaching of grammatical aspects. Some of the EL teachers mentioned that although the ETA Program helped in terms of building the students' confidence and interest in speaking English language, however, only some ETAs had emphasized on the grammatical aspects of the language.

The evidences obtained from interviewing both the head of EL panel and EL teachers indicated that the ETA Program does helped in enhancing students' confidence and interest in using English but the program does not have a profound effect in improving the students' overall EL proficiency.

\section{Discussion}

There are discrepancies in the language proficiency between students guided by ETAs and students who were not guided by ETAs. However, 
the mean score for both written test and oral test for students in co-teach classes were low and they did not obtain satisfactory level, despite getting guidance from ETAs and involved with most of the activities conducted by ETAs. It should be noted that most of the schools involved in this study had a minimum of two (2) years exposure since the ETA Program was implemented. Hence, in theory, the students' in coteach classes should be able to perform much better than the students in the non-co-teach classes, who were not guided by ETAs.

In comparison of the written test scores between Form 2 students in co-teach classes and students in non-co-teach classes, majority of the students obtained scores below 6 (mean score: 4.4 for coteach classes; 3.5 for non-co-teach classes). As for Form 4 students (category 2), the mean score for students' written test in co-teach classes is 3.74, while the mean score for non-co-teach class students is 1.6. Again, despite the significant differences of mean scores, the students' achievement for both forms was low and did not reach satisfactory level. Also, the mean scores for the students who were guided by ETAs were not significantly better than the mean scores for students in non-co-teach classes. Other than that, it is worth to note that some of the students in co-teach classes were not able to provide answer to the given topic and a few of the students left their answer sheet blank.

There are significant differences in oral test for both Form 2 and Form 4 students between co-teach classes and non-co-teach classes. Despite the significant differences of mean scores, the average marks were low, even for the students in co-teach classes. In addition, during the oral test, the researcher observed that majority of the students from co-teach classes were not able to convey their ideas during the oral test. Most of them were hesitant and were not confident while taking the oral test. Furthermore, during TaL observation, the researcher noticed that most students were struggling to build proper sentences and their lack of vocabulary affected them as well, while undertaking the oral test.

Theoretically, the students who were guided by the ETAs should perform significantly better and obtain higher scores than the students who were not guided by the ETAs. Based on the interview conducted, students claimed that the ETA Program helped greatly in improving their motivation and interest in study and using EL. However, despite the heightened and improved motivation among the students, the written and oral test scores of the students in the co-teaching classes were not significantly higher than the students in the non-coteaching classes. Consequently, this means that there is no significant correlation between motivation and EL proficiency of the students in this study. In a study conducted by Lah (1996), she noted that there were low to moderate correlation between both integrative and instrumental motivation and the achievement in second language. It is unclear how heightened motivation could lead to a better proficiency in the target language in this study.

\section{Conclusion}

The government has spent millions on the implementation of ETA Program under the MBMMBI Policy in hopes to improve Malaysian students in EL. Although findings in this study show that the program positively affected the students' motivation and interest in EL, however, the program is still far from perfect and there are many rooms for improvement to make the program effective in achieving its objectives.

This study has provided some insights on the actual implementation of the ETA Program. It is a commendable effort from the government to improve the EL proficiency of the Malaysian students, especially in the rural areas. Despite the flaws in the overall implementation of the ETA Program, it has successfully motivated most of the students in rural schools to learn and use EL. The program also brought noticeable and positive changes to certain school.

As a conclusion, the findings of this study show that the implementation of ETA Program had a positive impact on the students' motivation and interest in English language but the impact was minimal, given the fact that most of the schools involved in this study had received ETAs for at least 2 years. Other than that, although the ETAs helped in improving the students' motivation and interest in English, however, it did not have a profound effect on the students' overall English language proficiency.

\section{References}

August D and Shanahan T (2006). Developing literacy in secondlanguage learners: Report of the national literacy panel on language minority children and youth. Lawrence Erlbaum Associates, Mahwah, USA.

Bahfen, N., Abd Rahman, Z. A., \& Peers, J. (2014). Kampong (Village) Boy: Lat and Icons of Malaysian Nationhood. International Journal of Comic Art, 16(1), 487-499.

Cohen L, Manion L, \& Morrison K (2013). Research methods in education. Routledge, Abingdon, UK.

Gonzales P, Williams T, Jocelyn L, Roey S, Kastberg D, and Brenwald S (2007). Mathematics and Science Achievement of U.S. Fourth- and Eighth-Grade Students in an International Context. Statistical Analysis Report, The IEA's Trends in International Mathematics and Science Study (TIMSS), National Center for Education Statistics, Institute of Education Sciences, U.S. Department of Education. Washington, USA. Available online at: https://nces.ed.gov/pubsearch/pubsinfo .asp?pubid=2009001

Krejcie RV and Morgan DW (1970). Determining sample size for research activities. Educational and Psychological Measurement, 30(3): 607-610.

Lah CS (1996). Language attitudes towards English and language proficiency in English among Malaysian students: A sociolinguistic study of Penang Island. Ph.D. Dissertation, University of Reading, Reading, UK.

McCroskey JC (1970). Measures of communication-bound anxiety. Speech Monographs, 37(4): 269-277. 
Rahman ZAA (2012). Chronicling fifty years (1957-2007) of Malaysian identity. Ph.D. Dissertation, RMIT University, Melbourne, Australia.
Teddlie C and Yu F (2007). Mixed methods sampling: A typology with examples. Journal of Mixed Methods Research, 1(1): 77100. 